\title{
New principles will make dental complaints easier
}

Dental regulator the General Dental Council (GDC) and 27 other organisations are launching new complaint principles that are designed to make the process for dental patients to make a complaint easier and ensure they are handled better, starting at a local level.

The principles have been agreed by 28 organisations including the GDC, BDA, Care Quality Commission (CQC), NHS England, Health Education England (HEE), defence bodies, dental nurse and hygienist representative bodies and the Parliamentary and Health Service Ombudsman.

Collectively, the 28 organisations from across the dental sector joined forces to launch a set of universal principles for good complaint handling and formed the Profession-wide Complaint Handling Initiative Working Group.

The six core principles provide a simple template for best practice, helping professionals and patients to get the most from feedback and complaints, for the benefit of all, said the group, which was coordinated by the GDC.

The GDC said that according to its 2017 Public and Patient Survey, ${ }^{1} 97 \%$ of dental patients reported being either very $(67 \%)$ or fairly (29\%) satisfied with their dental treatment and only $8 \%$ reported having considered making a complaint.

However, of those who had considered making a complaint, around a third (33\%) said they had not actually done so because they did not know where to start.

The six core principles to communicate to patients that will be available in poster form are: - All of your feedback is important to us
- We want to make it easy for you to raise a concern or complain, if you need to

- We follow a complaints procedure and keep you informed

- We will try to answer all your questions and any concerns you raise

- We want you to have a positive experience of making a complaint

- Your feedback helps us to improve our service.

It is hoped that the principles will be clearly displayed and accessible in every clinical setting providing dental care by May 2019.

GDC Executive Director for Strategy, Matthew Hill, said: 'We all know that good complaint and feedback handling is an important part of being a dental professional which is why we committed to developing a profession-wide understanding of what best practice looks like.

'There was really strong support from across the sector for this, so a working group was formed which went on to develop the six core principles. These set out a very clear picture of what patients can expect when providing feedback or making a complaint.'

Chair of the BDA's Education, Ethics and the Dental Team Working Group, Alison Lockyer, welcomed the principles, saying: 'The $\mathrm{BDA}$, together with indemnity organisations, the NHS, CQC and HEE, among others, has developed a set of materials for use in practice, with the simple objective to ensure complaints are handled first at local level.

'The dental practice is the best place to go to when a patient feels that they wish to raise an issue, and resolve it quickly and practically.

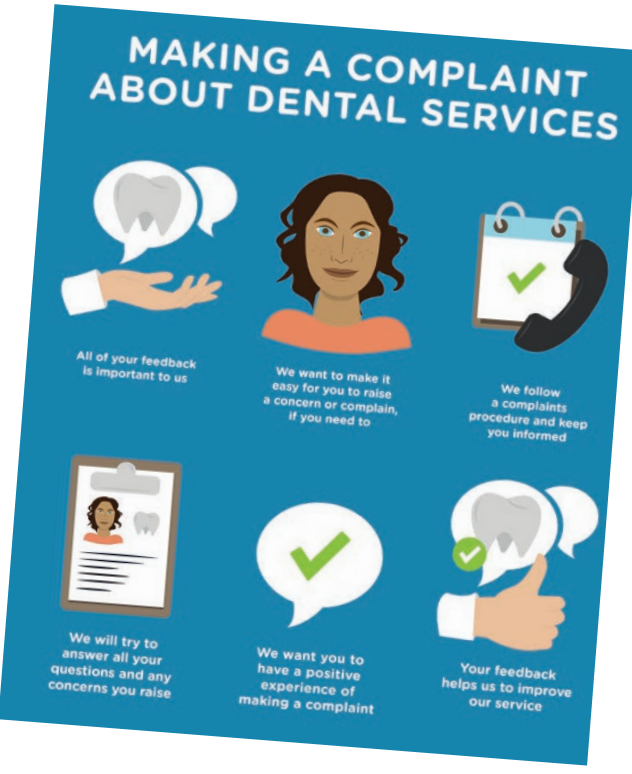

The resources use simple

language and are designed to benefit patients and practitioners, and also help to reflect the regulatory and contractual requirements that are in place. We all win if complaints that would have been made to the GDC - or a solicitor - are made to the practice instead.'

Director of Primary Care Commissioning at NHS England, Dr David Geddes, added: 'Local resolution to complaints should always be encouraged and this work will hopefully help dental practices be more confident in their complaint handling.'

More information and supporting resources, including a poster and leaflet, are available electronically from many of the working group members' websites.

1. General Dental Council. Patient and Public Survey 2017 2017. Available at https://www.gdc-uk.org/about/whatwe-do/research/patient-and-public-survey (accessed November 2018).

\section{BDJ RESEARCH INSIGHTS BU FOR ANOTHER VIEW}

- Research insights from across the BDJ Portfolio

- Providing busy readers with valuable context including article summaries and expert commentary

Catch up here: http://bit.ly/BDJResearchlnsights

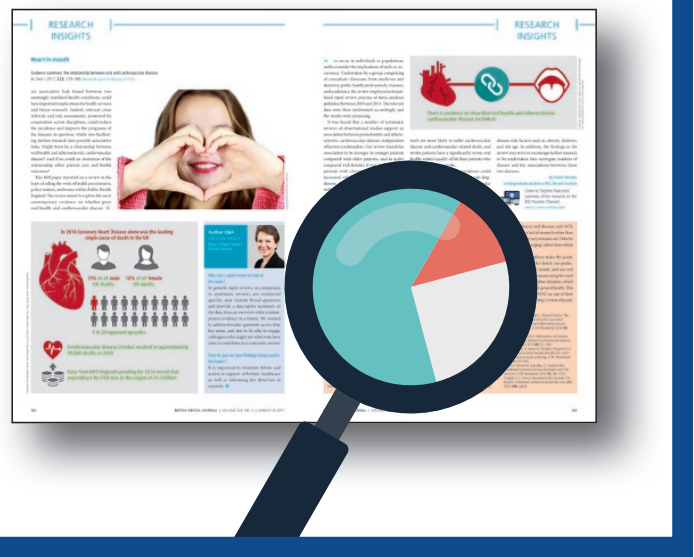

